Prácticas patrimoniales en el contexto de la celebración por el centenario del primer despacho de cemento en Argentina

María Eugenia Conforti, Griselda Lemiez, María Vanesa Giacomasso y María Luz Endere

páginas / año 12 - n 30 Septiembre-Diciembre / ISSN 1851-992X/ 2020

http://revistapaginas.unr.edu.ar/index.php/RevPaginas

DOI: http://dx.doi.org/10.35305/rp.v12i30.446

\title{
Prácticas patrimoniales en el contexto de la celebración por el centenario del primer despacho de cemento en Argentina
}

\section{Patrimonial practices in the context of the centennial celebration of the first Cement dispatch in Argentina}

\begin{abstract}
María Eugenia Conforti
Consejo Nacional de Investigaciones Científicas y Técnicas; Instituto de Investigaciones Arqueológicas y Paleontológicas del Cuaternario Pampeano;

Programa Interdiscipinario de Estudios del Patrimonio;

Facultad de Ciencias Sociales;

Universidad Nacional del Centro de la Provincia de Buenos Aires (Argentina) mariaeugeniaconforti@gmail.com
\end{abstract}

Griselda Lemiez

Consejo Nacional de Investigaciones Científicas y Técnicas; Instituto de Investigaciones Arqueológicas y Paleontológicas del Cuaternario Pampeano; Programa Interdiscipinario de Estudios del Patrimonio; Facultad de Ciencias Sociales; Universidad Nacional del Centro de la Provincia de Buenos Aires (Argentina) griseldalemiez@gmail.com

María Vanesa Giacomasso

Consejo Nacional de Investigaciones Científicas y Técnicas; Instituto de Investigaciones Arqueológicas y Paleontológicas del Cuaternario Pampeano; Programa Interdiscipinario de Estudios del Patrimonio; Facultad de Ciencias Sociales; Universidad Nacional del Centro de la Provincia de Buenos Aires (Argentina) vanegiaco05@gmail.com

María Luz Endere

Consejo Nacional de Investigaciones Científicas y Técnicas; Instituto de Investigaciones Arqueológicas y Paleontológicas del Cuaternario Pampeano; Programa Interdiscipinario de Estudios del Patrimonio; Facultad de Ciencias Sociales; Universidad Nacional del Centro de la Provincia de Buenos Aires (Argentina) luz.endere@gmail.com 


\title{
María Eugenia Conforti, Griselda Lemiez, María Vanesa Giacomasso, María Luz Endere
}

\section{Resumen}

En este trabajo se presentan y analizan un conjunto de actividades enmarcadas en la conmemoración del centenario del primer despacho de cemento de Argentina que se realizó en el año 1919 desde la Fábrica de Cemento San Martín, ubicada en la localidad de Sierras Bayas, partido de Olavarría, Buenos Aires. Su abordaje metodológico se basó en el estudio de casos cualitativos referidos a: tres exhibiciones y un monumento conmemorativo construido e instaurado con motivo del aniversario. Este acontecimiento histórico, vinculado con los inicios de la industria minera, marcó un hito fundamental en la identidad del partido de Olavarría ya que contribuyó a su crecimiento poblacional, económico y social que repercutió, además, en la consolidación de su imagen como "ciudad del cemento". A 100 años del primer despacho, las acciones de activación del patrimonio industrial buscaron comunicar su historia con marcas particulares y distintivas. En este punto, este estudio cobra relevancia porque permite identificar los procesos de puesta en valor del patrimonio local, los principales grupos de interés y los desafíos futuros que afronta esta comunidad a partir de las transformaciones recientes.

\section{Palabras clave}

Patrimonio industrial; Puesta en valor; Activación patrimonial; Historia del cemento; Identidad local; Argentina.

\begin{abstract}
In this paper, a set of activities carried out in the framework of the commemoration of the centenary of the first cement dispatch in Argentina are presented and analysed. It took place in 1919 from the San Martín Cement Factory, located in the town of Sierras Bayas, County of Olavarría, Buenos Aires province. The methodological approach was based on the study of qualitative cases referred to three exhibitions and a memorial monument built on the occasion of the anniversary. This historical event, linked to the beginnings of the mining industry in the region, marked a fundamental milestone in the identity of the county of Olavarría as it contributed to its population, economic and social growth that also affected the consolidation of its image as "the city of cement". One hundred years after the first dispatch, the activation actions of the industrial heritage sought to communicate its history with particular and distinctive brands. At this point, this study becomes relevant because it allows us to identify the processes of value assessment of the local heritage, the main stakeholders and the future challenges of this community in the face of recent transformations.
\end{abstract}

\section{Keywords}

Industrial heritage; Enhancement; Heritage activation; Cement history; Local identity; Argentina. 


\section{Prácticas patrimoniales en el contexto de la celebración por el centenario del primer despacho de cemento en Argentina}

El partido de Olavarría, ubicado en el centro de la provincia de Buenos Aires (Figura 1) se constituyó desde principios del siglo XX como un área minera por excelencia, a partir de la instalación de empresas dedicadas a la producción de cal y cemento. En ese contexto, en el año 1919 se realizó desde la Fábrica San Martín, radicada en la localidad de Sierras Bayas el primer despacho de cemento de Argentina. Esta fue la primera fábrica de cemento de Sudamérica, de propiedad de la Compañía Argentina de Cemento Portand, de capitales tejanos. El envío del primer despacho marcó un hito en la historia del pueblo, del partido y del país. En el año 2019, se cumplió su centenario, motivo por el cual, desde diferentes sectores de la comunidad se desarrollaron un conjunto de actividades y exposiciones conmemorativas. En este trabajo se presentan y analizan los principales eventos efectuados en vinculación con dicho festejo con el fin de reconstruir los sentidos e imágenes que refuerzan la asociación de Olavarría como la "ciudad del trabajo" y la "ciudad del cemento".

Es interesante destacar que son sólo algunas localidades del partido de Olavarría (principalmente Sierras Bayas, Loma Negra y Sierra Chica) las que están asociadas a explotaciones mineras y que ello no ocurre con la ciudad de Olavarría, cabecera de partido, que está ubicado lejos de las sierras y en la planicie de inundación del arroyo Tapalqué. Sin embargo, en el discurso oficial se ha instalado desde hace décadas el slogan "Olavarría ciudad del trabajo" (asociado al boom minero fabril que atraía obreros de otros países y de otras regiones) o "ciudad del cemento", cuando en realidad debería hacerse referencia al partido. Esta cuestión referida a los imaginarios sociales de la ciudad de Olavarría ha sido objeto de diferentes investigaciones (Boggi, 2005; Gravano, 2005, 2015).

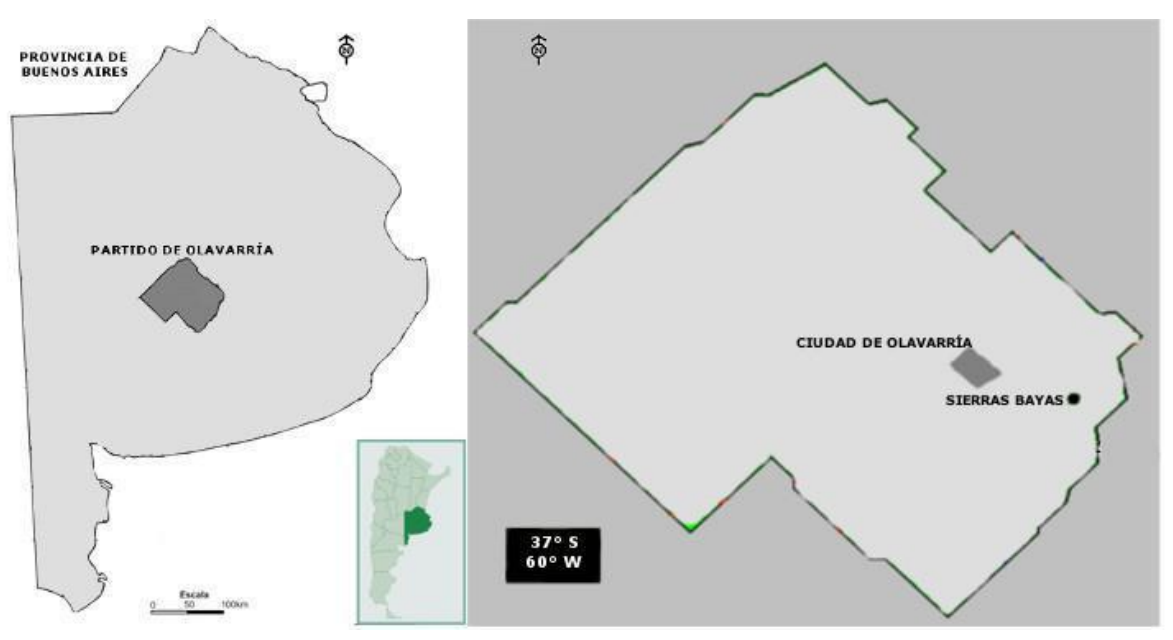

Figura 1. Ubicación del partido de Olavarría. Fuente: Autoras. 


\section{María Eugenia Conforti, Griselda Lemiez, María Vanesa Giacomasso, María Luz Endere}

Cabe destacar que Olavarría se ha consolidado históricamente en base a su patrimonio industrial minero, el cual contribuyó al desarrollo económico y al crecimiento poblacional que posicionó al partido como un polo industrial, a nivel nacional e internacional. Por esta razón, no es casual que las celebraciones por el centenario hayan activado una serie de procesos de puesta en valor de ese legado histórico y movilizado a diferentes sectores y actores sociales vinculados, directa e indirectamente con él, para visibilizar su importancia.

En este sentido, en el marco de este trabajo se identificaron cuatro casos de estudio: tres exhibiciones y una monumentalización, que comenzaron a diseñarse y ejecutarse a partir del año previo del centenario (2018) y que acompañaron las celebraciones del aniversario más allá de la fecha exacta de febrero 2019. La primera, fue una muestra que tuvo lugar en setiembre de 2018 y que se denominó "ADN Olavarría, raíces mineras"; mientras que la segunda fue la exposición "Historia del Cemento Portland en Argentina" efectuada en noviembre de 2018. En 2019 se inauguró una tercera exhibición denominada "Centenario del primer despacho de cemento de la Planta Sierras Bayas". Finalmente, el cuarto episodio considerado para este análisis fue la instalación del monumento "100 años del primer despacho de cemento (1919-2019)" que se ubicó en el predio de la fábrica cementera de Sierras Bayas, coincidiendo con el lugar desde donde se realizó el primer despacho de Cemento Portland del país.

Para el abordaje metodológico se trabajó con el Estudio de Casos Cualitativos (Galeano Marin, 2004; Stake 1994) tomando en consideración a estas cuatro manifestaciones conmemorativas. A partir de este trabajo se espera contribuir al análisis en torno a los procesos de puesta en valor ${ }^{1}$ del patrimonio industrial en el partido de Olavarría y a la discusión crítica sobre el uso de estrategias de comunicación y visibilización que refuerzan unas determinadas memorias e identificaciones locales por sobre otras.

\section{El partido de Olavarría y el desarrollo de la industria minera (1919-2019)}

El Partido de Olavarría se encuentra ubicado en el centro geográfico de la provincia de Buenos Aires, Argentina. Además de la ciudad cabecera, que fue fundada en 1867, está integrado por las localidades de Sierra Chica, Loma Negra, Sierras Bayas, Hinojo, Colonia Hinojo, Colonia San Miguel, Colonia Nievas, Cerro Sotuyo, La Providencia, Espigas, Recalde, Santa Luisa, Durañona, Pourtalé, Rocha, Mapis, Muñoz, Iturregui y Blanca Grande. Olavarría se posiciona en la actualidad como "el principal distrito minero de la provincia" y ocupa el primer lugar en la minería no metalífera nacional (i.e. áridos y rocas de aplicación) (Municipalidad de Olavarría, 2016).

\footnotetext{
${ }^{1}$ En este trabajo se utiliza el concepto de puesta en valor (ver definición más adelante en el apartado teórico) pero además nos referiremos a él con otras expresiones a las que le atribuimos un significado equivalente tales como "valoración", "activación del patrimonio" o "proceso de patrimonialización".
} 


\section{Prácticas patrimoniales en el contexto de la celebración por el centenario del primer despacho de cemento en Argentina}

El desarrollo industrial de Olavarría se puede dividir en dos grandes etapas: la primera de ellas, conocida como etapa preindustrial abarca el período comprendido entre 1870 y 1917 y se destaca por la gran producción de granito y cal; la segunda, es la industrial profesional de fábrica que se estableció a partir de la primera instalación de una empresa de cemento en Sierras Bayas en 1917, la cual comenzó su producción en 1919. El éxito de la primera industria moderna y la disponibilidad de piedra caliza y arcilla en la zona, incentivaron nuevas inversiones. En el año 1926 fue inaugurada la primera planta de Loma Negra S.A, propiedad de Alfredo Fortabat, siendo esta la primera empresa de capital argentino que utilizó una tecnología de producción continua. Por último, en el año 1932 se suma a estas empresas cementeras Calera Avellaneda S.A., que se caracterizó por elaborar el cemento con las más modernas tecnologías de su tiempo. "A partir de esta fecha, cuando estas empresas se instalaron en el partido, la actividad minera se convirtió en el principal recurso económico de la región" (Lemiez \& Conforti, 2019:3).

La antigua forma de producción, envasado y comercialización del cemento requería gran cantidad de mano de obra, que además debía residir en las cercanías de las fábricas debido a las características del ciclo continuo de producción del cemento. Asimismo, estas debían situarse cerca de los yacimientos mineros y canteras, como consecuencia del escaso desarrollo del transporte y la infraestructura de caminos. La instalación de la industria extractiva en la zona serrana olavarriense motivó la iniciación del desarrollo económico-productivo local y que actuó como disparador de atracción de población, conformando un enorme mercado de trabajo que era hasta ese momento inexistente. En esos espacios rurales y en las poblaciones cercanas no había una oferta suficiente de trabajadores, por lo tanto, la necesidad de atraerlos y fijar su residencia en las proximidades de las plantas se convirtió en una tarea prioritaria para las empresas cementeras (Lemiez, 2013).

En consecuencia, las denominadas "villas obreras" o "villas serranas", levantadas casi a la sombra de cada fábrica, fueron producto de esa necesidad de contar con un mercado de trabajo estable. En ellas se desarrollaron políticas patronales de corte paternalista, destinadas a la fijación y adaptación de la mano de obra, también llamadas "obras sociales" (Sierra Álvarez, 1990). Estos modelos empresariales conocidos como sistema de fábrica con villa obrera (Neiburg, 1998), en donde la esfera de producción y reproducción de la fuerza de trabajo se encontraban estrechamente unidas y moldeadas por relaciones sociales y laborales paternalistas, funcionaron hasta la década de 1980.

Actualmente, el Partido de Olavarría ocupa un lugar muy importante en la producción minería no metalífera. El trabajo en minas y canteras representa el 38,5\% del Producto Geográfico Bruto (PGB), según los datos de la Dirección de Estadísticas y Censos, de acuerdo al PGB desagregado municipal del año 2003. En los últimos tiempos la producción minera en la ciudad de Olavarría se ha convertido en un sector de alto crecimiento a nivel económico y comercial, debido al incremento del área de la construcción y de la obra pública. Esto conlleva al aumento de inversiones y desarrollo de actividades en los ámbitos asociados. 


\section{María Eugenia Conforti, Griselda Lemiez, María Vanesa Giacomasso, María Luz Endere}

Adicionalmente, dicho crecimiento genera un impacto positivo en diversos sectores tales como agrupamientos industriales, transportes, sector comercial y de servicios, y de mano de obra indirecta, entre otros. Actualmente, la industria minera de Olavarría posee recursos estratégicos para su desarrollo, tales como el granito, la caliza y la dolomita, y los subproductos derivados del proceso industrial como el cemento (Municipalidad de Olavarría, 2016).

\section{Aspectos teóricos y metodológicos del trabajo}

\section{El patrimonio cultural e industrial}

La historia del desarrollo de la industria minera cementera y las memorias asociadas se convirtieron en un legado que se fue transmitiendo de generación en generación y que llega hasta la actualidad, constituyendo una importante marca de identidad para el partido de Olavarría que se manifiesta a través del patrimonio cultural, en general y del patrimonio industrial, en particular (Alfrey \& Putnam, 2003).

$\mathrm{Al}$ respecto, es necesario referir al concepto de patrimonio cultural que se entiende como una construcción social constituida por bienes materiales e inmateriales como las costumbres, los conocimientos, los sistemas de significados y formas de expresión simbólica- que determinados grupos desean preservar como parte de su historia e identidad (Bond \& Gilliam, 1994; García Canclini, 1999; Prats 2000, 2007; Rosas Mantecón, 2005; Endere, 2009). Esto da cuenta de su carácter relacional, inseparable de las experiencias y prácticas humanas y de las significaciones, percepciones y valoraciones que los grupos producen sobre su espacio y territorio. Por lo tanto, el "patrimonio" es en última instancia una práctica cultural, involucrada en la construcción y regulación de una gama de valores y entendimientos (Smith, 2006: 11).

En este sentido, resulta interesante abordar la relación que se establece entre la comunicación y el proceso de puesta en valor del patrimonio cultural, cualquiera sea su tipo. En términos de Grimson (2000) “comunicar" supone una relación social y significa "poner en común"; es decir la producción de un código compartido para que un elemento cualquiera pueda convertirse en significante al interior de una determinada estructura colectiva. Por ello es que se entiende que "poner en valor" constituye la acción de "poner en común" que aplica para el proceso de activación patrimonial (Conforti, 2013). La puesta en valor de un bien cultural -o de un conjunto de bienes- se fundamenta, principalmente, en el aprecio social del mismo, basado en sus cualidades representativas. Conlleva implícita la protección (del bien o de aquello que representa) y su objetivo culmina con la difusión pública para fomentar su perdurabilidad y memoria a través de la interpretación. La intención de generar empatía con el público que lo apreciará se constituye en una acción de fortalecimiento de la cultura e identidad de un colectivo social. 


\section{Prácticas patrimoniales en el contexto de la celebración por el centenario del primer despacho de cemento en Argentina}

En suma, el valor del patrimonio cultural se relaciona, entre otras cosas, con su función de representación de la memoria histórica; como seña de identidad, como proceso de reconocimiento intergeneracional que da sentido a la pertenencia de grupo y de comunidad; la cual se presenta ante los demás a través de su patrimonio (Ballart,1997).

Sin embargo, la construcción del patrimonio está atravesada por dimensiones políticas, y también económicas, que hacen que dicha construcción lejos de ser un proceso neutral o inocente, se active ${ }^{2}$ de acuerdo a determinadas ideas, valores e intereses diversos que se ponen en juego en situaciones históricas concretas (Prats, 2000). De acuerdo a este postulado, en la mayoría de los casos las activaciones que predominan se caracterizan por procesos Top-Down ("de arriba a abajo") en detrimento de procesos Botton-Up ("de abajo a arriba") de promoción del trabajo colaborativo y de participación ciudadana.

En estos procesos, la comunicación, como construcción e intercambio de sentidos y productos simbólicos, ejerce un papel central en relación con las dinámicas culturales, tanto para legitimar expresiones hegemónicas, como para disputar y negociar discursos y prácticas (Giménez, 2007).

Por otra parte, en relación con el patrimonio industrial puede afirmarse que este surge como emergente de diversas actividades que tuvieron y siguen teniendo profundas consecuencias históricas. Su valor social se encuentra en la impronta que fue dejando en la población y que se refleja en un sentimiento que contribuyó a la construcción de la identidad (Wicke \& Golombek, 2018). Está presente en las maquinarias, en el paisaje industrial, en la documentación escrita, y también en los registros intangibles de la industria almacenados en los recuerdos y las costumbres de los actores sociales que fueron parte un determinado contexto (Álvarez-Areces, 2008).

De este modo, el patrimonio industrial le da un sustrato material a la historia comunitaria y a la memoria colectiva. Las fábricas y sus villas obreras, como elementos de arquitectura y arqueología industrial, y el amplio elenco del patrimonio intangible convierten a los paisajes postindustriales en verdaderos territorios-museo. Diversos casos y experiencias nacionales e internacionales, arquetipos de regiones con vestigios notables de la revolución industrial sirven para ilustrar los límites y posibilidades de los programas de desarrollo regional a partir del turismo cultural (Rojek \& Urry, 1997). La integración de la arqueología industrial y los bienes culturales supone un reto para recomponer territorios o espacios singulares y hacer más habitables los entornos urbanos. Una apuesta y una

\footnotetext{
${ }^{2}$ Se entiende que los bienes patrimoniales son repertorios que se activan por ideas y valores, subsidiarios de los intereses de quienes los propugnan y comparten. De acuerdo a esta concepción es posible entender las diversas activaciones patrimoniales, no solo como representaciones simbólicas de ciertas versiones de la identidad, sino también como estrategias políticas, al servicio de intereses determinados.
} 


\section{María Eugenia Conforti, Griselda Lemiez, María Vanesa Giacomasso, María Luz Endere}

oportunidad que supone la puesta en valor del patrimonio industrial, natural y cultural como fundamento de una política territorial (Álvarez-Areces, 2008).

Cabe destacar que en el partido de Olavarría existen pasivos mineros productos de antiguas explotaciones a cielo abierto que no han sido remediadas y que constituyen remanentes de la minería protoindustrial (en el sentido de Paz 2009). Esto es particularmente evidente en la localidad de Sierras Bayas en donde se conservan antiguos hornos y caleras en la propia planta urbana. Sin embargo, son aún escasos los vestigios materiales relacionados con la industria del cemento, dado que la producción industrial continúa siendo actualmente el motor económico regional. Por este motivo se considera necesario interpretar el patrimonio industrial no como un elemento aislado propio del pasado, sin vinculación con el contexto social y económico actual (ver ICOMOS \& TICCIH 2011), sino en la dinámica de la vida cotidiana. Si bien el patrimonio industrial incluye una materialidad diversa: edificios, máquinas, utillaje, objetos, archivos, infraestructuras productivas, viviendas, se corresponde con un patrimonio intangible no menos significativo que está asociado a la memoria de sus protagonistas. De este modo, la patrimonialización en sociedades mineras (tan necesitadas de estímulos y transformación) se convierte en un campo de expectativas, proyectos e ilusiones para la población local, al tiempo que posiciona al patrimonio minero en articulador de procesos de acción social (Hernández Ramírez \& Ruiz Ballesteros, 2005a: 118).

\section{La metodología de estudios de casos}

En cuanto a los aspectos metodológicos este trabajo se basa en un enfoque de investigación cualitativa (Bodgan \& Taylor, 1992) fundado en el estudio de casos, entendido como una estrategia investigativa de descripción e interpretación a partir de un conjunto de materiales concretos y reales, estructurados con ese fin (Galeano Marín, 2004). El caso (como unidad de investigación) se estudia en sí mismo y en correlación con otro/s, como acontecimiento significativo de una dinámica de determinado grupo en su marco sociocultural particular (Pérez Serrano, 1994). Los cuatro casos analizados, son eventos y/o elementos conmemorativos que se utilizaron para poner en valor el patrimonio industrial de Olavarría en el marco del centenario del primer despacho de cemento de Argentina. Se trata de propuestas diferentes que son presentadas y estudiadas, primero de manera individual, y puestas luego en relación para su interpretación y análisis (Uribe, 1993). Para ello se combinó una serie de estrategias que consistieron en la observación participante (Woods, 1987) de las mencionadas actividades que fue posteriormente completada, por un lado, con un trabajo de registro fotográfico y audiovisual, y por el otro, con el análisis documental (Erlandson, 1993) que incluyó diversas fuentes (material periodístico, folletería, libros de visitas y archivos disponibles en Internet, etc.). Finalmente, y para complementar los estudios de caso se procedió a realizar entrevistas en profundidad (Guber, 2011) que permitieron contextualizar los festejos del centenario en cada uno de los eventos analizados. 


\section{Prácticas patrimoniales en el contexto de la celebración por el centenario del primer despacho de cemento en Argentina}

La Puesta en valor del centenario del primer despacho de cemento portland de Argentina. Presentación de casos y análisis.

En términos de Vélez Restrepo y Galeano Marín (2002), los casos de estudio seleccionados tienen el carácter de ser participativos ya que "se centran en una situación, evento, programa o fenómeno particular", es decir que son cada uno importante por lo que revela del fenómeno (en este caso, de la puesta en valor del patrimonio industrial minero local) y por lo que puede representar para su análisis. Cabe destacar que los estudios de casos resultan apropiados para investigaciones como la que aquí se presenta, es decir, de pequeña escala en un marco histórico limitado de tiempo, espacio y recursos. En este sentido, como proceso de descripción sistemática y de análisis, el presente estudio de casos pretende construir conocimiento sobre las regularidades del proceso social de puesta en valor del patrimonio industrial minero, identificando las particularidades y los patrones recurrentes en las mismas, así como las tensiones y las contradicciones que plantean.

Antes de iniciar la presentación de los eventos analizados, cabe aclarar que por definición el estudio de caso lleva implícita la descripción (Stake 1994). La presentación y narración en detalle que sostiene un caso constituye una base importante del análisis, ya que brindará los sustentos propios así como los de su puesta en relación con otros. Frente a esta decisión metodológica general es que se exponen a continuación cada uno de los cuatro "eventos" que constituyen nuestras unidades de análisis (casos). La descripción que los presenta es necesariamente pormenorizada y extensa, ya que los detalles y particularidades de cada uno ponen de manifiesto las cuestiones más importantes que constituyen los ejes de discusión y análisis de este trabajo.

\section{- Caso 1. "ADN. Raíces Mineras"}

En Olavarría, los festejos conmemorativos por el centenario del primer despacho de Cemento comenzaron en el año 2018. La Municipalidad, a través de la Secretaría de Desarrollo Económico ${ }^{3}$, organizó la exhibición itinerante "ADN Olavarría. Raíces Mineras". Esta muestra se llevó a cabo entre el 24 y 30 de setiembre en la Casa del Bicentenario, un edificio municipal que es usado para actividades sociales y culturales. En dicha exhibición "se propuso un recorrido por los orígenes de los olavarrienses, a través de sus actividades productivas mineras, con el objetivo de poner en valor el patrimonio histórico e industrial local" (Municipalidad de Olavarría 2018). La dinámica del evento consistió en una semana completa de actividades: entre los días 24 y 28 la exposición estuvo abierta solo a visitas

${ }^{3}$ El evento fue organizado en conjunto por la Secretaría de Desarrollo Económico -a través de sus Direcciones de Minería y Turismo- y la Subsecretaría de Cultura y Educación, además se sumaron empresarios industriales. 


\section{María Eugenia Conforti, Griselda Lemiez, María Vanesa Giacomasso, María Luz Endere}

escolares programadas ${ }^{4}$, el día 29 se realizó la inauguración oficial y en dicho marco se efectuó además un reconocimiento a actores vinculados al sector minero (Figura 2). Finalmente, durante la jornada del domingo 30 se abrió la exhibición al público en general, con la utilización de diversos recursos expositivos, incluyendo paneles infográficos, realidad virtual y exposición de piezas originales cedidas en préstamo por el Museo Municipal de la Piedra "Emma Occhi" de la localidad de Sierra Chica (principalmente herramientas de hierro empleados para la extracción manual de la piedra y su posterior procesamiento) (Figura 3).

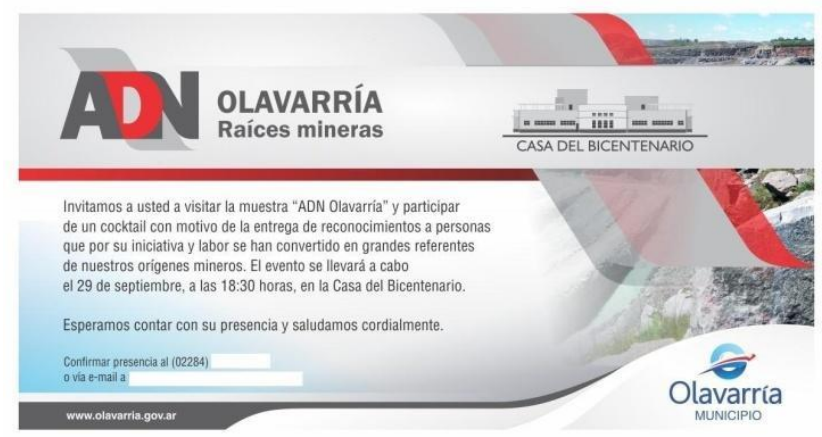

Figura 2. Tarjeta de invitación a la inauguración de la exhibición ADN. Fuente: Autoras.

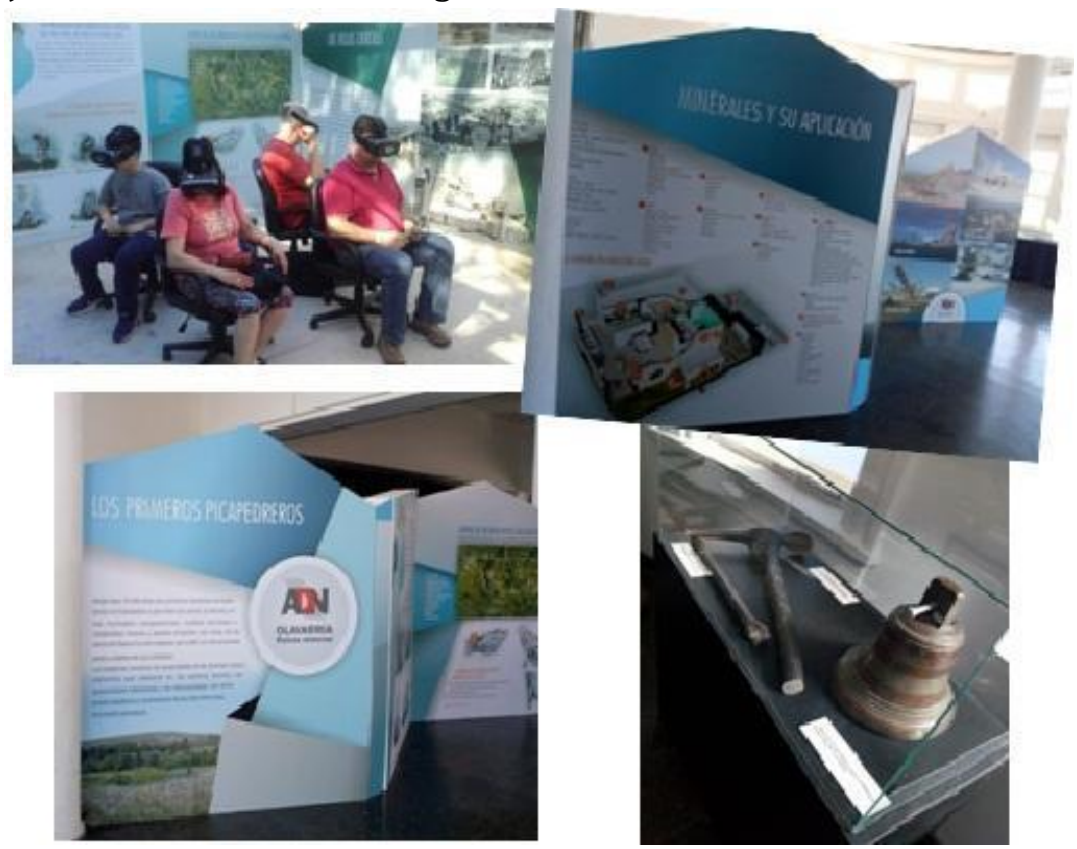

Figura 3: Imágenes representativas de la exposición ADN. Fuente: Autoras.

La muestra se completó con la exhibición de actividades artesanales en vivo (realización de modelado en arcilla y talla de piedra del taller de picapedreros y

\footnotetext{
${ }^{4} \mathrm{~A}$ los grupos escolares de nivel primario y secundario se les ofrecían visitas guiadas, a cargo de personal de la Municipalidad que se desempeña en el área de Museos, y se les entregaba un material bibliográfico con información sobre los contenidos de la muestra para su tratamiento en el aula.
} 


\section{Prácticas patrimoniales en el contexto de la celebración por el centenario del primer despacho de cemento en Argentina}

escultores) (Figura 4), eventos musicales y ferias gastronómicas. Según datos públicos, alrededor de 1.500 personas asistieron a la exhibición en el transcurso de la semana que tuvo de duración 5 .

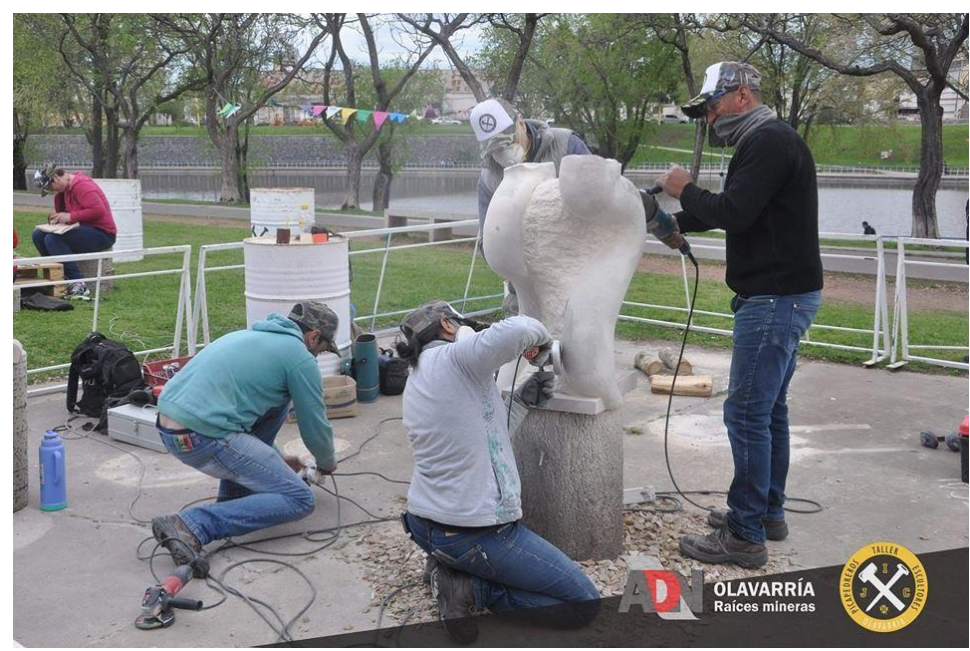

Figura 4. Escultura del eslabón de la cadena de ADN realizado en vivo por integrantes del Taller de Picapedreros y Escultores. Fuente: Municipalidad de Olavarría.

El eje temático que orientó el guión fue el uso histórico de la piedra como recurso natural local. La exhibición principal fue montada sobre paneles móviles dando versatilidad al armado y a la adaptación espacial. Los contenidos abarcaron una amplia línea de tiempo que se inicia hace 15 mil años, con la utilización de las canteras para la confección de instrumentos líticos por parte de los grupos indígenas que habitaron el territorio. Luego se describe la producción minera artesanal de mano de obra inmigrante durante fines del siglo XIX y principios del XX, destacando el rol de las familias pioneras, tanto en la producción de la cal como en el trabajo de la piedra. Culmina el relato con el desarrollo de la industria cementera a gran escala, a partir de la segunda década del siglo XX, que conllevó a la instalación de las Villas Obreras como modalidad habitacional. En el cierre se hace hincapié en la aplicación de los minerales extraídos de Olavarría y su impacto en la vida cotidiana. Finalmente, la narración llega hasta el presente enfatizando la vigencia y el auge de las empresas cementeras del partido y su gravitación en la economía regional.

La historia desarrollada a través de los diferentes paneles fue construida sobre infografías, a partir de textos apoyados con imágenes. Se utilizaron dibujos originales realizados por una artista plástica local y fotos de archivo cedidas por investigadores, familias pioneras, empresas y el Archivo Municipal. Los recursos complementarios fueron piezas de museo y filmaciones en $4 \mathrm{k}$ que permitieron, a través de la utilización de cascos virtuales, apreciar diferentes escenas actuales del proceso de extracción y producción minera local, por ejemplo, la rotación $360^{\circ}$ para

${ }^{5}$ Fue visitada por 14 escuelas, contabilizando un total de 850 estudiantes; 200 personas participaron de la inauguración oficial y la entrega de reconocimientos y el día domingo asistieron 450 visitantes (https://lu32.com.ar/nota/66916/importante-convocatoria-en-adn-olavarria-raices-mineras) 


\title{
María Eugenia Conforti, Griselda Lemiez, María Vanesa Giacomasso, María Luz Endere
}

apreciar las voladuras de frentes de cantera ${ }^{6}$ y el transporte de materia prima desde un camión volquete. Para su construcción los organizadores solicitaron el asesoramiento a la Facultad de Ciencias Sociales local (UNICEN) que, a través de sus investigadores, brindó apoyo en la elaboración de los contenidos.

Resulta oportuno destacar los reconocimientos que se efectuaron a diferentes actores de la actividad minera local. Los premios se dividieron en seis categorías y se distinguió a obreros activos y retirados, empresarios y familias pioneras de la zona (Tabla 1 ).

\begin{tabular}{|c|c|}
\hline CATEGoRÍA & DISTINCIONES \\
\hline INDUSTRIADEL CEMENTO & $\begin{array}{l}+\quad 4 \text { premios entregados a obreros y jubilados de Loma Negra } \\
+\quad 1 \text { premio entregado a jubilado de Cementos Avellaneda } \\
+\quad 2 \text { premios entregados a jubilados de la ex fábrica San Martín. }\end{array}$ \\
\hline INDUSTRIA DE LA CAL & $\begin{array}{l}+\quad 1 \text { obrero premiado por POLCECAL. } \\
+\quad 1 \text { obrero premiado por Buglioney Martinesse. }\end{array}$ \\
\hline PIEDRAPARTIDA & $\begin{array}{l}+\quad 2 \text { premios entregados a obreros y jubilados de Cantera Piatti. } \\
+\quad 2 \text { premios entregados a jubilados de Cantera Adolfo Guerrico. }\end{array}$ \\
\hline PICAPEDREROS & $\begin{array}{l}\text { + } 3 \text { artesanos premiados por su labor manual de la extracción y manufactura artesanal de la } \\
\text { piedra. }\end{array}$ \\
\hline $\begin{array}{l}\text { FAMILIAS PIONERAS DE LA } \\
\text { MINERÍA }\end{array}$ & $\begin{array}{ll}+ & \text { Familia Colombo (Italiana). } \\
+ & \text { Familia Piatti (Italiana). } \\
+\quad \text { Familia Aust (Alemana). } \\
+\quad \text { Familia Gregorini (Italiana). }\end{array}$ \\
\hline EMPRESAS PIONERAS & $\begin{array}{l}\text { + Loma Negra CIASA, premiada por sus } 3 \text { plantas locales productoras de cemento, incluidala } \\
\text { ex fäbrica San Martin. } \\
+\quad \text { Cementos Avellaneda, primada por su planta local. } \\
+\quad \text { Cantera Cerro Negro, premiada por su planta local. }\end{array}$ \\
\hline
\end{tabular}

Tabla 1. Detalle de reconocimientos entregados en el marco de la muestra "ADN Olavarría. Raíces Mineras" (Fuente: registros de Autoras).

En esta oportunidad el único orador fue el intendente Municipal Ezequiel Galli, quien destacó que

\begin{abstract}
“cuando nace este evento (ADN Olavarría. Raíces Mineras), nos motivó la importancia de reconocernos en los valores que han potenciado nuestra ciudad y la necesidad de revisar nuestro pasado, nuestras raíces y nuestra historia para entender lo que moldea la impronta minera e industrial de Olavarría; y que ha dado lugar a que nos posicionemos como ciudad referente del centro de la Provincia de Buenos Aires...La minería y la industria nos han dado la posibilidad de posicionarnos como referentes de la región impulsando desarrollo, tecnología y conocimiento, generando valor agregado desde varios aspectos, logrando así configurar una Olavarría pujante y transformadora identificada como tal, no sólo en el ámbito local, sino también en la provincia y en todo el país"7.
\end{abstract}

\footnotetext{
${ }^{6}$ Las "voladuras" son explosiones que se realizan a cielo abierto para la extracción de materia prima (rocas), generando así un pozo profundo denominado cantera.

${ }^{7}$ https://lu32.com.ar/nota/66916/importante-convocatoria-en-adn-olavarria-raices-mineras
} 


\section{Prácticas patrimoniales en el contexto de la celebración por el centenario del primer despacho de cemento en Argentina}

En este discurso se reflejan las intenciones de empresarios y autoridades de poner en valor este recurso como acción de patrimonialización tendiente a reflotar, reforzar e intensificar en el presente local la impronta minera desde una arista netamente productiva que posiciona actualmente, así como a lo largo de la historia, a Olavarría en los mercados nacionales e internacionales.

A partir del nombre de la muestra "ADN Olavarría. Raíces mineras" se apela a la minería como el constituyente principal del "material genético de los olavarrienses", invisibillizando otros componentes de la identidad local. Este sesgo también se evidencia en todos los aspectos de la exhibición que fue organizada por el personal del municipio, basándose en textos de expertos y que no incluye en su guión las opiniones de los protagonistas cotidianos (obreros y vecinos), quienes son puestos en escena por otros y a partir de reconocimientos externos. A pesar de que en la jornada de inauguración se presentaron videos realizados por la productora de contenidos audiovisuales de la Facultad de Ciencias Sociales de Olavarría con el testimonio de quienes fueran los seleccionados para la premiación, podría concluirse que tuvieron una visibilidad menor.

Cabe destacar que esta muestra fue exhibida sólo en dos oportunidades, una durante la semana de su inauguración en setiembre de 2018, y otra, en el mes de noviembre de 2018, durante la realización de un Congreso Internacional sobre Hormigón Armado (ver a continuación el caso 2 de este apartado).

\section{- Caso 2. "Historia del Cemento Portland en Argentina"}

Una segunda actividad directamente vinculada con el aniversario de los 100 años del primer despacho de cemento fue la exposición denominada "Historia del Cemento Porland en Argentina”, la cual estuvo abierta al público en general, en el marco del Congreso Internacional del Hormigón que se llevó a cabo en la ciudad de Olavarría en noviembre de 2018. Precisamente la razón por la cual esta ciudad fue sede del congreso se relaciona con los festejos por el centenario, tal como lo expresó el ingeniero local Fabián Irassar, docente e investigador de la Facultad de Ingeniería de Olavarría, una de las instituciones intervinientes en la organización del evento:

\footnotetext{
"Este Congreso tiene la particularidad de llevarse a cabo en el marco del centenario del primer despacho del Cemento Portland que salió de Sierras Bayas, que se cumple en febrero de 2019. Esto redunda en beneficios vinculados a la obra pública y la infraestructura de la que hace uso toda la sociedad"8.
}

La vinculación del evento con la historia local y la economía regional se expresa claramente en las palabras del Intendente Ezequiel Galli quien, en la conferencia de prensa inaugural, sostuvo: "Para nosotros, como capital del cemento, es un orgullo poder contar con este Congreso, en un momento donde tenemos grandes inversiones en la ciudad, con una proyección muy positiva para toda la zona"g.

${ }^{8}$ https://www.olavarria.gov.ar/se-presento-el-congreso-internacional-del-hormigon/
${ }^{9} \underline{\mathrm{https}: / / \text { www.olavarria.gov.ar/se-presento-el-congreso-internacional-del-hormigon/ }}$ 


\section{María Eugenia Conforti, Griselda Lemiez, María Vanesa Giacomasso, María Luz Endere}

En este congreso, desarrollado en el Centro de Convenciones Olavarría (CCO), además de realizarse presentaciones referidas a temas diversos relacionados a los diferentes tipos de cemento (los procesos, propiedades, residuos sólidos industriales y municipales; las obras de hormigón, históricas y actuales; las estructuras del patrimonio arquitectónico, etc.), se llevaron a cabo actividades complementarias como visitas técnicas a los Centros de Investigación Tecnológica y a las Fábricas de Cemento de Olavarría, así como conferencias, paneles de obras y exposiciones conmemorativas sobre la historia del cemento.

La exposición fotográfica, que tuvo una duración de una semana, se expuso en un espacio del CCO de gran circulación y de tránsito de los participantes del congreso hacia otra sala donde se encontraba expuesta la muestra "ADN Olavarría, Raíces Mineras". La idea de exhibir reproducciones de fotografía históricas surgió a propuesta de la Asociación de Fabricantes de Cemento Portland y contó con la colaboración del Grupo de Investigación en Antropología y Arqueología Industrial (GIAAI) de la Facultad de Ciencias Sociales de la ciudad. Dicho grupo dirigido por el Dr. Carlos Paz, participó en la selección y edición de fotografías vinculadas a la minería local y que formaban parte del archivo digital del mencionado grupo, que cuenta con más de 2500 fotografías y videos recopilados a lo largo de dos décadas de trabajo.

La muestra se centró en 12 imágenes en total (Figura 5) que cuentan cronológicamente la historia de la producción cementera local, desde la década de 1940 -con una primera fotografía que muestra desde arriba la "Fábrica de Loma Negra"- hasta una última imagen del año 1999, en donde se puede observar la “Fabrica San Martín” de Sierras Bayas, también desde una toma aérea.

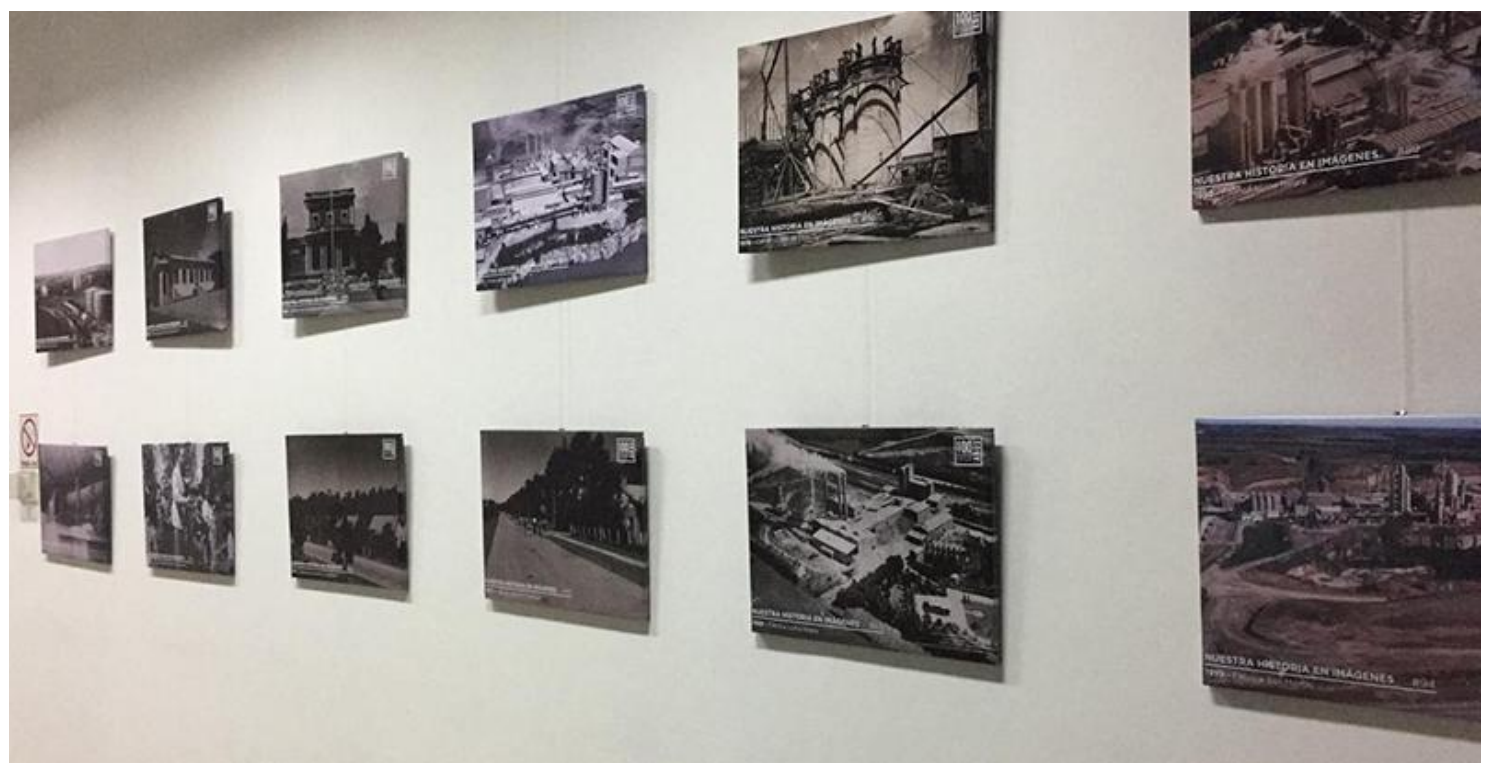

Figura 5. Imágenes de la muestra "Historia del Cemento Portland en Argentina", expuestas en el CCO. Fuente: Autoras.

Las fotografías que siguen a la primera muestran "La Compañía Argentina de Cemento Portland" en el año 1943 y en los años 50 a los "Edificios para Oficinas y 


\section{Prácticas patrimoniales en el contexto de la celebración por el centenario del primer despacho de cemento en Argentina}

Laboratorios" (1955); a "Alfredo Fortabat con gente del pueblo" (1956) y al "Edificio de la Escuela de Sierras Bayas” (1958). De los años '60 no se presentan fotografías y de los años '70 se exponen las "Casas de empleados y capataces"; la "Vista Aérea de Fábrica" (1971) y también la "Calle principal de Hormigón" (1973) y la "Construcción de Silos" (1978). Entre las últimas imágenes se incluyeron dos fotografías de la "Fábrica Loma Negra”, una de 1980 y otra de 1990 (Figura 6).

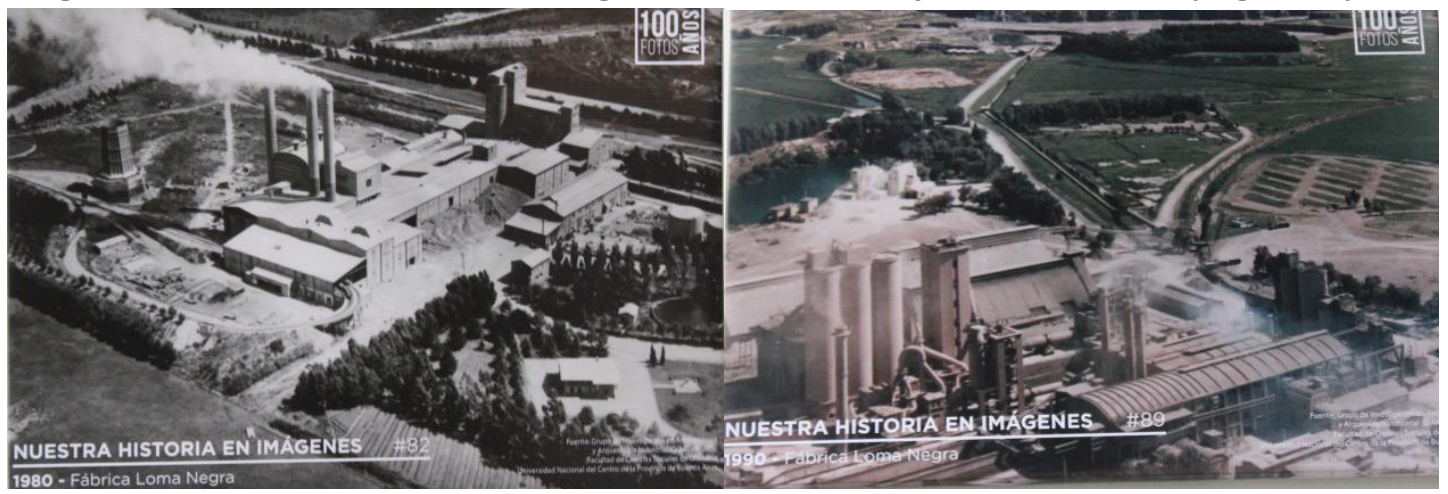

Figura 6. Imágenes de la muestra "Historia del Cemento Portland en Argentina", expuestas en el CCO. Fuente: Autoras.

De esta exposición se destaca un anclaje puesto en lo visual, ya que la muestra no contiene texto, así como en la fotografía como fuente documental de una historia local ligada a la industria del cemento, donde prima el registro sobre la fábrica $y / u$ otros edificios asociados con esta, como sus oficinas y laboratorios. Sin embargo, la vida alrededor de este modelo de producción, se observa solo a través de imágenes de las viviendas de empleados y capataces y de la escuela del barrio, aunque en ellas se prescinde de la población. La participación de los vecinos se observa sólo en dos oportunidades: una como anexo del concepto central de la fotografía que versa sobre las calles de hormigón, donde pueden verse niños en el fondo; y otra, donde el protagonista de la imagen es Alfredo Fortabat emitiendo un discurso sobre un escenario rodeado de vecinos del pueblo (Figura 7). Esta imagen demuestra una presencia sobresaliente de este personaje por sobre otros, que se rescata como la única figura omnipresente de la historia cementera local.

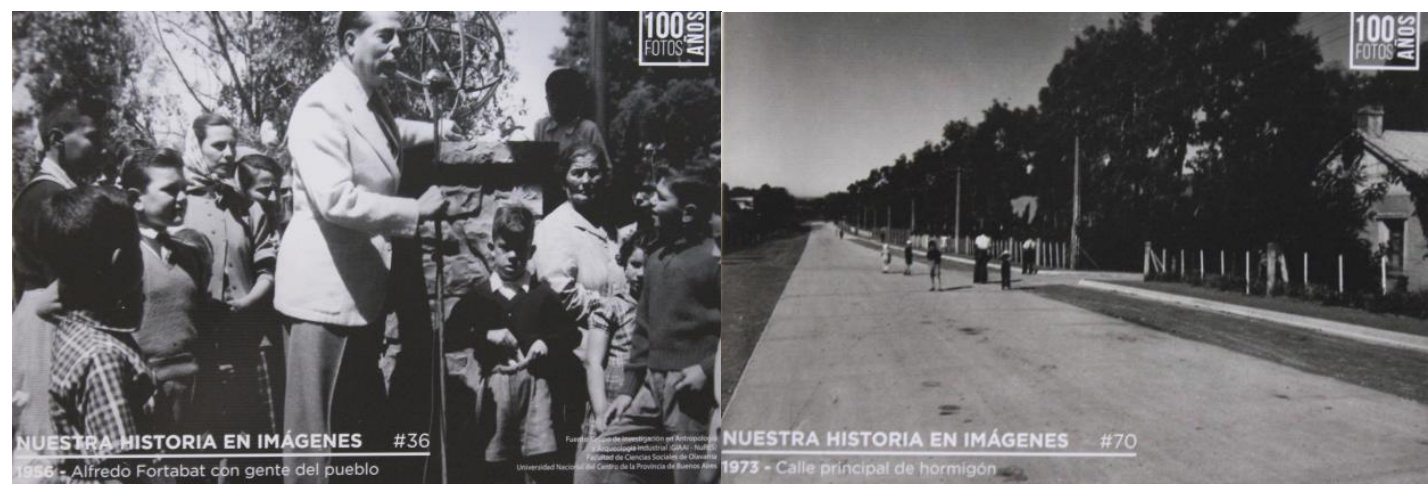

Figura 7. Imágenes de la muestra "Historia del Cemento Portland en Argentina", expuestas en el CCO. Fuente: Autoras. 


\section{María Eugenia Conforti, Griselda Lemiez, María Vanesa Giacomasso, María Luz Endere}

- Caso 3. "Centenario del primer despacho de cemento de Planta Sierras Bayas" Con el objetivo de conmemorar el centenario del primer despacho de cemento Portland de la fábrica de Sierras Bayas, en el Museo Municipal de la Estación de dicha localidad, se organizó una exhibición que tenía como propósitos presentar la historia de la fábrica San Martín y dar a conocer las tradiciones de un pueblo vinculado estrechamente al trabajo del cemento. Dicha muestra buscó acercar a los visitantes a los estilos de vida de la villa obrera, tomando como referencia el trabajo específico en la fábrica, los quehaceres cotidianos y el modo en que todo el conjunto de las relaciones sociales estaban permeadas por una actividad minera que dejó sus huellas identitarias en la comunidad sierrabayense. La inauguración se realizó el día 10 de febrero de 2019.

La exhibición incluyó un registro fotográfico, textos e instalaciones, material audiovisual y escenográfico que ofrecieron al visitante información variada para comprender la relevancia que tuvo esa fábrica en la construcción de la identidad comunitaria local.

Luego de su inauguración, la muestra permaneció en el Museo de la Estación de Sierras Bayas durante tres meses. Si bien la invitación fue dirigida al público en general, se hizo especial hincapié en la difusión a la comunidad educativa para que concurrieran docentes y estudiantes de las escuelas primarias y secundarias de la ciudad de Olavarría y sus localidades.

En el museo, cada uno de los espacios fueron utilizados para representar - con fotografías, imágenes y planos- la historia de la industria de cal y cemento en Sierras Bayas y los actores que fueron parte de este proceso desde sus inicios hasta la actualidad (Figura 8). Presentadas en un orden cronológico con sus respectivas informaciones, las diversas gigantografías ilustraron las etapas por las que fue transitando la empresa cementera (Figura 9). Cabe destacar que al ingresar por la puerta principal del Museo se encontraba la máquina original utilizada por los trabajadores del cemento para "marcar tarjeta" al inicio y finalización de su jornada laboral y que también servía como control del pago mensual y quincenal. Esto representó un gran atractivo para los estudiantes, quienes tuvieron la oportunidad de marcar una tarjeta tal como lo hacían sus antepasados, los obreros de fábrica.
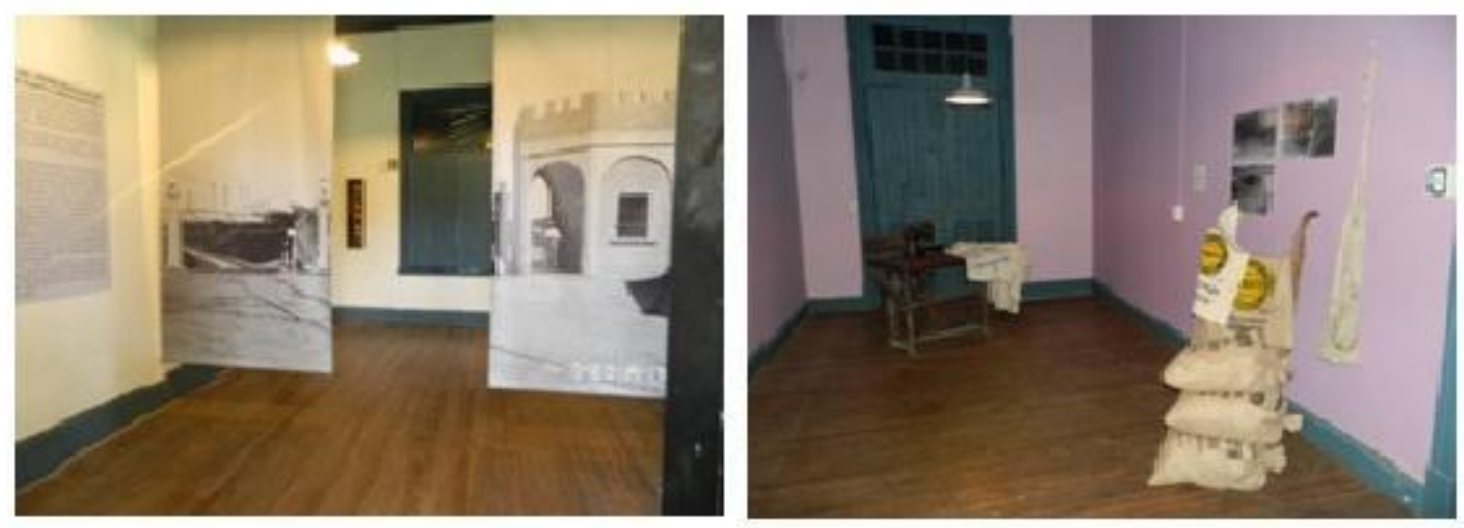

Figura 8. Izquierda Sala 1(ingreso a la Exhibición). Derecha Sala 2 ("la embolsadora"), Museo de la Estación de Sierras Bayas. Fuente: Autoras. 


\section{Prácticas patrimoniales en el contexto de la celebración por el centenario del primer despacho de cemento en Argentina}

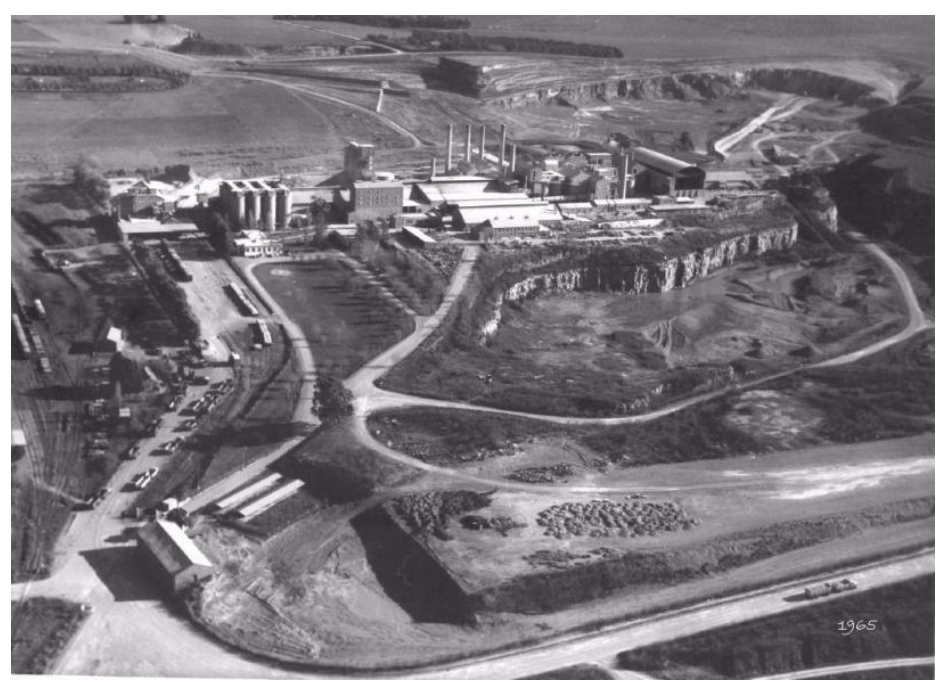

Figura 9. Fotografía aérea de la fábrica San Martín de la Compañía Argentina de Cemento Portland en Sierras Bayas, año 1965. Fuente: colección del Museo de Sierras Bayas.

También se expusieron las primeras bolsas de tela blanca utilizadas para envasar y despachar el cemento Portland y las máquinas de coser utilizadas para su elaboración, así como la impresión del logo de la empresa en color azul. Esas bolsas adquirieron a lo largo de los años un alto valor simbólico en la historia de todos los sierrabayenses. La máquina de coser cumplió un rol muy importante dentro de la empresa, ya que significó la fuente de trabajo de decenas de mujeres, que se encargaban de reparar las bolsas que retornaban a la fábrica. Se exhibieron además las primeras camisetas de fútbol utilizadas para representar al Club Social y Deportivo de Sierras Bayas. El dato anecdótico en relación a la importancia de la actividad industrial cementera en el pueblo es que los colores que representaban al club (amarillo y negro) fueron tomados del logo de la empresa.

La muestra también incluyó un sector destinado para la exposición de la obra perteneciente al artista plástico sierrabayense Daniel Fitte, llamada "Guantes usados por obreros de una fábrica productora de cal" que representa un homenaje constante al obrero. Para realizarla, los trabajadores le facilitaron sus guantes, sus herramientas y sus prendas, a fin de que pudieran ser plasmados en una obra que se complementaba a la perfección con la muestra del centenario del primer despacho de cemento Portland. Según Fitte, el sentido principal fue -a través de estos objetos materiales- otorgarle voz propia a esos trabajadores, visibilizar con objetos la actividad industrial y poder rescatar el patrimonio cultural de la comunidad. La obra de Daniel Fitte se construye en base al legado material y simbólico del pueblo de Sierras Bayas, lugar donde nació, vive y trabaja. Este artista considera que las huellas del trabajador sobre una pala constituye "el espíritu vivo de quien las usa, sus guantes, la piel más fiel y las herramientas que lo acompañan todos los días, como su DNI"10.

${ }^{10} \underline{\mathrm{http}}$ ://www.lu32.com.ar/movil/nota.php?ID=3219 


\section{María Eugenia Conforti, Griselda Lemiez, María Vanesa Giacomasso, María Luz Endere}

Cabe destacar que el día posterior a la inauguración de esta exposición en el Museo de la Estación (11 de febrero de 2019) se realizó un acto protocolar conmemorativo, también en la localidad de Sierras Bayas, específicamente en el lugar donde se emplaza el monumento en homenaje al Trabajador del Cemento ${ }^{11}$. Si bien este acto no constituye una acción de puesta en valor vinculada al proceso de patrimonialización aquí abordado, representa una instancia más de resignificación que permite recuperar las voces de diversos actores sociales (locales, regionales y nacionales), mediante sus discursos alusivos al centenario.

La celebración comienzó luego del tradicional sonido del silbato que cien años atrás marcaba el inicio de la jornada laboral, posteriormente tomaron la palabra los representantes de la Asociación de Fabricantes de Cemento Portland y del Instituto Argentino de Cemento Portland. En sus discursos coincidieron en destacar a este evento como algo representativo de toda la industria argentina, señalando la relación directa que existe entre la industria cementera y las diferentes actividades propias de la vida cotidiana "donde el cemento interviene en todos nosotros a través de las diferentes construcciones materiales como por ejemplo los hogares, las escuelas, los hospitales y las rutas".12 Aseguraron que "era un honor" poder compartir con la comunidad de Sierras Bayas este momento tan importante de conmemoración de los cien años de la primera bolsa de cemento despachada desde la industria nacional, acontecimiento que permaneció presente en el desarrollo del país y que continúa en la actualidad. ${ }^{13}$

También se calificó al evento como una "fiesta de los trabajadores" que fueron los actores centrales y encargados de construir esta realidad. Se insistió en considerar al cemento como "la máxima expresión de la industrialización del valor agregado argentino a un producto minero", y se mencionó el recorrido por los establecimientos industriales y los yacimientos de rocas, destacando las inversiones necesarias para incrementar la productividad y la economía en todo el país.

Asimismo se recordó la historia de la ciudad de Olavarría, en dos momentos, por un lado se hizo referencia al un fuerte militar de 1870 protegía a los comerciantes de los "aborígenes" y, por el otro a las primeras décadas del 1900, cuando se lograría obtener lo que hoy es el cemento.

Para cerrar los discursos, el intendente de Olavarría aseguró que para los olavarrienses es muy importante estar cumpliendo cien años del comienzo de la fabricación del cemento, además destacó que "actualmente se está produciendo el cincuenta por ciento del cemento del país, lo que posiciona a la ciudad en una situación de privilegio y de absoluta responsabilidad". Celebró que las cementeras

\footnotetext{
11 Dicho monumento se inauguró también un 10 de febrero del año 2010, al conmemorarse el 91음 aniversario del primer despacho de cemento. La obra fue realizada por el artista plástico local Daniel Fitte y organizado por el Rotary Club serrano. http://www.sierrasbayas.com.ar/HISTORIA/CEMENTO/monumentotrabajadordelcemento.html 12 https://enlineanoticias.com.ar/secciones/ciudad/sierras-bayas-a-un-siglo-del-primer-despachode-cemento

${ }^{13}$ https://enlineanoticias.com.ar/secciones/ciudad/sierras-bayas-a-un-siglo-del-primer-despachode-cemento/
} 


\section{Prácticas patrimoniales en el contexto de la celebración por el centenario del primer despacho de cemento en Argentina}

que están ubicadas en Olavarría estén llevando adelante inversiones para seguir creciendo, para "seguir produciendo ese cemento tan necesario para la vida cotidiana de todos los argentinos". Caracterizó "estos cien años, como cien años de producción, de trabajo" y, además, expresó el gran deseo de que esto continúe creciendo y que "Olavarría siga siendo la capital del cemento para poder estar presente en cada punto del país".

Posteriormente se descubrió una placa recordatoria de la celebración del centenario y se dio paso a la entrega de reconocimientos a más de 40 personas que estuvieron ligadas a la industria cementera y que ocuparon diferentes puestos de trabajo en la fábrica.

La intención de hacer mención a este acto en el contexto de las múltiples celebraciones por el centenario fue la de ofrecer mayores elementos de comparación a fin de poder contrastar los diferentes ámbitos y actores involucrados, lo que resulta útil para caracterizar la relación actual que los diferentes agentes sociales establecen, tanto con la historia como con la producción actual de cemento. Cabe destacar que, por un lado, en la exhibición del museo se planteó como principal objetivo el de acercar al visitante a conocer la vida laboral y social que proponía la fábrica, mientras que por otro, quienes representan los intereses políticos y económicos de la industria (tanto a nivel nacional como provincial y local), ponen el acento en resaltar la importancia que tuvo, y sigue teniendo, la producción cementera para el desarrollo del país y concretamente para la ciudad de Olavarría. No obstante, quienes fueron los actores más inmediatos y centrales en este proceso, es decir los trabajadores y las familias obreras de Sierras Bayas, lejos de rescatar los aspectos vinculados a lo material y a lo económico, le otorgan a la instalación y permanencia de la muestra en el museo otro sentido: el de reconstruir la historia de Sierras Bayas y dar a conocer las marcas identitarias que la producción de cemento fue dejando en toda la comunidad y que mantienen su vigencia.

\section{- Caso 4. "Monumento conmemorativo del centenario del primer despacho"}

Finalmente, la construcción de un monumento en el acceso a la localidad de Sierras Bayas también fue parte de las actividades que rememoran los comienzos de la industria minera en la localidad. La escultura fue realizada por el artista plástico local Juan Ignacio Cardiello, quien fue convocado por el municipio, la empresa Loma Negra y el Rotary Club local (Figura 10). Consta de tres piezas con un gran valor simbólico que se construyeron utilizando elementos originales vinculados a la industria cementera. La base (primer pieza) está realizada con una antigua herramienta llamada moledora de piedras calizas, el № 100 (segunda pieza) fue construido con cemento y, por último, una antigua bolsa de cemento (tercera pieza) fue recreada con piedra dolomita tallada, una roca característica de la zona que forma parte del legado minero de la localidad de Sierras Bayas ${ }^{14}$.

\footnotetext{
${ }^{14}$ https://www.verte.tv/noticias/2758-Monumento-por-los-100-anos-del-primer-despacho-decemento
} 


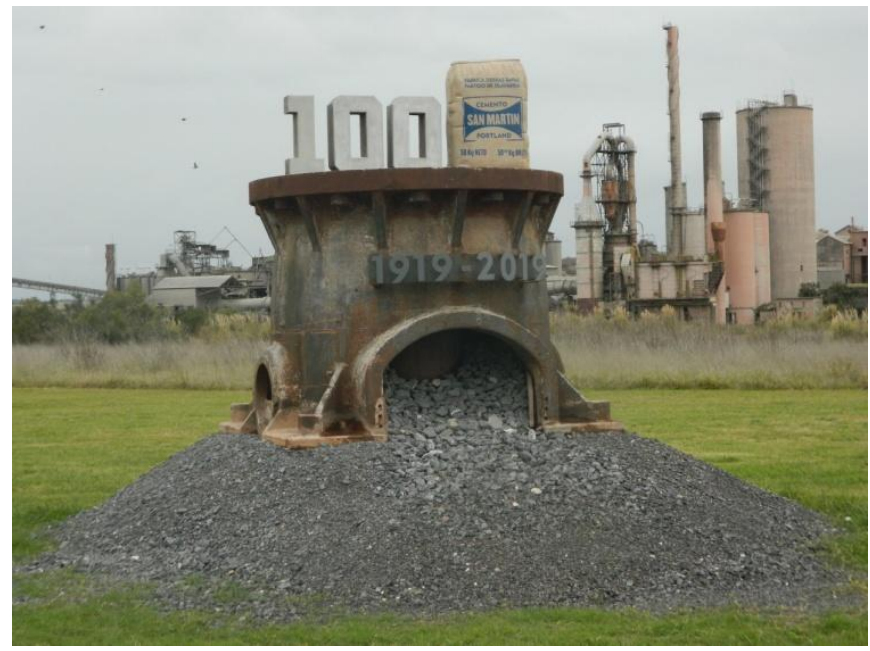

Figura 10. Monumento inaugurado en febrero de 2019 al conmemorarse los 100 años del primer despacho de cemento Portland. Fuente: Autoras.

La importancia de esta pieza escultórica radica, más allá de su valor artístico, en su carga simbólica, es decir en su capacidad para representar la significación del centenario para este pueblo pionero en particular, pero también para la comunidad toda de Olavarría. La monumentalización posee un significado social e histórico vinculado a los patrimonios de determinadas comunidades, porque tiene la capacidad de evocar hechos, acontecimientos, vivencias, en tanto testimonio tangible de una determinada cultura, de un modo de hacer o, como en este caso, de un modo de producción y de vida asociada a ella, que marcó una época emblemática en el partido. Si bien actualmente existen otros tipos de estrategias de puesta en valor menos restringidas que la de la instalación de un espacio y un elemento conmemorativo, este modo clásico continúa estando vigente en el imaginario social, ya que remite a un pasado como testimonio de un período de la historia que ya no existe, que se desea recordar, que a menudo se idealiza (Samuel, 1994; Lowenthal, 1998) y que conlleva implícita la idea de preservar y proteger la materialidad remanente. Paradójicamente, el monumento fue emplazado en febrero de 2019, en el predio de la fábrica que en septiembre del mismo año anunciaría su cierre definitivo para ser reemplazada por una nueva planta procesadora con tecnología más avanzada, emplazada en la localidad de Loma Negra. De este modo la fábrica de Sierras Bayas ha quedado en desuso, ${ }^{15}$ convirtiéndose en un pasivo industrial de destino incierto. Esta situación tiene un impacto a nivel nacional, regional pero también local, ya que dota al monumento realizado por Cardiello de un valor aún mayor para la comunidad sierrabayense ya que no sólo simboliza el pasado sino también el presente incierto de la colectividad minera, situación que es contradictoria con el contexto de celebraciones que marcó el inicio del mismo año.

\footnotetext{
${ }^{15}$ https://www.clarin.com/economia/economia/loma-negra-cierra-planta-cemento-antiguapais 0 KEqclz0h.html
} 


\section{Prácticas patrimoniales en el contexto de la celebración por el centenario del primer despacho de cemento en Argentina}

\section{Conclusiones}

En este artículo se presentaron las diferentes actividades de rememoración y puesta en valor que se realizaron en la ciudad de Olavarría y en la localidad de Sierras Bayas en el contexto de las celebraciones por el centenario del primer despacho de cemento de Argentina. A lo largo de este trabajo se hizo hincapié en la diversidad de acciones que fueron gestadas por los diferentes sectores sociales, por lo que las celebraciones fueron adquiriendo en dicho proceso improntas particulares y distintivas. En ese marco cabe preguntarse, ¿quiénes fueron los principales interesados en movilizar estos procesos de activación patrimonial? ¿Qué aspectos se seleccionaron para ser visibilizados en el marco de la conmemoración del centenario y cuál fue el rol -primero previsto y luego efectivo- de la comunidad? Como se mencionó anteriormente, en rasgos generales, la activación se realizó "desde arriba", con el asesoramiento de expertos y muy escasa participación social de vecinos, trabajadores y ex trabajadores, por lo que el rol previsto para ellos fue el de destinatarios, asimilados al público en general. En cada uno de los casos, puede apreciarse que los sectores vinculados a la gestión política y económica de la ciudad fueron los protagonistas, actuando algunos investigadores de ámbitos académicos locales desde el rol de asesores expertos.

Esta cuestión no es menor ya que, tanto en el guión de las muestras, como en los discursos de los representantes del sector público y empresarial, se presentan de manera indiscutidas algunas cuestiones como la valoración de la industria minera, del progreso, así como la necesidad efectuar permanentes cambios, acompañando el desarrollo económico del país. Sin embargo, ese discurso se contrasta con la realidad cotidiana de Sierras Bayas impactada por las marcas territoriales que deja la explotación minera en el propio casco urbano, el cierre de la emblemática fábrica que, dada su ubicación estratégica domina el paisaje sierrabayense, al que se suman los hornos históricos abandonados y los pasivos mineros que dejan los pozos de las canteras en desuso y que van dando lugar al "fantasma" del paisaje posindustrial en el corazón mismo de la localidad.

De modo que no es extraño esperar que sus habitantes experimenten una fuerte nostalgia por los tiempos pasados, por aquella "época de oro" de una fábrica que demandaba gran cantidad de mano de obra y de un modo de vida que estaba dominado por los ritmos que imponía la dinámica laboral, incluidas las celebraciones anuales, como la Fiesta Nacional del Cemento (ver Giacomasso, Lemiez \& Conforti, 2019). En los testimonios que se recogieron en las producciones audiovisuales se destaca precisamente el orgullo por el trabajo minero y la nostalgia por las épocas de auge de la localidad.

Así, el mundo del trabajo cargado por los emblemas de la fábrica está siempre presente en las diferentes evocaciones del pasado, en las muestras e exhibiciones locales, en las obras de los artistas, que usan materiales reciclados, en la camiseta del club local que aún conserva los mismos colores y en los saberes tradicionales que se intentan transmitir, como las técnicas de los picapedreros artesanales. 


\section{María Eugenia Conforti, Griselda Lemiez, María Vanesa Giacomasso, María Luz Endere}

En ese marco, se abre un panorama incierto para la localidad que se irá configurando con mayor agudeza en las próximas décadas. Esa nostalgia del pasado puede, no obstante, servir para promover una actitud valorativa de todos estos vestigios que ha dejado el mundo del trabajo fabril y que son susceptibles de poner en valor. Esta no es una cuestión menor si se reconoce que el patrimonio cultural contribuye, además, a la promoción de sentidos de pertenencia, integración y responsabilidad; así como la producción de acciones democráticas en asuntos de interés común (UNESCO, 2014). La puesta en valor del patrimonio natural y cultural de la zona es sin duda un desafío a asumir, no sólo desde el espacio de la conmemoración, sino a través de una gestión sostenible. La remediación de antiguos pasivos mineros, la preservación de instalaciones industriales, maquinarias y herramientas, así como de otros edificios que forman parte del conjunto fabril y la villa obrera serán todo un desafío para los próximos años, así como la recuperación de las memorias asociadas. Las recientes actividades de conmemoración -analizadas aquí como casos- se presentan como hechos aislados y sin intención de continuidad. No se observa desde la gestión gubernamental una política patrimonial que vaya un poco más allá del discurso y las buenas intenciones. La comunidad local, por su parte, demanda una acción permanente de preservación y de rememoración, así como un espacio que se constituya en un repositorio de esa memoria social; lo que supera ampliamente lo desarrollado hasta el momento. El museo local ubicado en la antigua Estación de Tren se encuentra en malas condiciones edilicias y carece de una muestra permanente que dé cuenta de la historia sierrabayense en su integralidad. Mientras tanto queda pendiente una verdadera reflexión comunitaria sobre el futuro postindustrial de Sierras Bayas, así como una planificación desde la gestión política, con la participación ciudadana, que abra nuevos horizontes para la población local. La reconversión de las estructuras fabriles en un patrimonio industrial susceptible de generar nuevas oportunidades para el turismo sustentable local (ICOMOS, 1999; Richards, 2000) será, sin duda, uno de los grandes temas de discusión. Cabe destacar que para el patrimonio minero se constituya en un articulador de procesos sociales y generador de dinámicas culturales de revalorización comunitaria, se requiere que "la patrimonialización dé el salto al ámbito de influencia de la política local”, como señalan Hernández Ramírez \& Ruiz Ballesteros (2005a: 118). En efecto, la sinergia entre una política sostenida de puesta en valor del patrimonio y el interés e iniciativa de la comunidad local es esencial para activar estos procesos y darle largo aliento. Las experiencias desarrolladas en otros sitios y lugares del patrimonio industrial dan muestra y sin duda refuerzan esta afirmación (Alfrey \& Putnam, 2003; Hernández Ramírez \& Ruiz Ballesteros, 2005b; Álvarez-Areces, 2008).

\section{Agradecimientos}

Agradecemos a los referentes de cada uno de los casos analizados en este artículo por ceder su testimonio, así como permitir el acceso a los espacios presentados para su registro. Este trabajo fue realizado en el marco del programa Interdisciplinario 


\section{Prácticas patrimoniales en el contexto de la celebración por el centenario del primer despacho de cemento en Argentina}

de Estudios del Patrimonio (PATRIMONIA), del Instituto de Investigaciones Arqueológicas y Paleontológicas del Cuaternario Pampeano (INCUAPA-UE CONICET), con financiamiento proveniente de los subsidios dirigidos por la Dra. María Luz Endere: PIP CONICET 1122015 - 0100106 CO “Estudio de las significaciones sociales del patrimonio cultural del partido de Olavarría, provincia de Buenos Aires. Propuesta metodológica para su visibilización y salvaguarda” y PICT ANPCyT 0551/2106 "Investigación, Gestión y Significación Social del Patrimonio Cultural en el Centro de Buenos Aires y Centro-Este de San Luis", y de la Dra. María Eugenia Conforti: PICT ANPCyT 0624/2017, "Patrimonio arqueológico y comunidad local. El caso del partido de Benito Juárez, provincia de Buenos Aires".

\section{Bibliografía}

Alfrey, J. y Putnam, T. (2003). The Industrial Heritage. Managing Resources and Uses. Londres: Routledge.

Álvarez-Areces, M. (2008). Patrimonio industrial. Un futuro para el pasado desde la visión europea. Apuntes. Revista de Estudios Sobre Patrimonio Cultural 21(1). Recuperado de https://revistas.javeriana.edu.co/index.php/revApuntesArq/article/view/8963

Ballart, J. (1997). El Patrimonio Histórico y Arqueológico: valor y uso. Madrid: Ariel.

Bogdan, S. y Taylor, R. (1992). Introducción a los métodos cualitativos de investigación social. Barcelona: Paidós.

Boggi, S. (2005). El orgullo de haber sido y el dolor de ya no ser: Olavarría en la mirada de sus líderes. En A. Gravano (comp.); Imaginarios sociales de la ciudad media, emblemas, fragmentaciones y otredades urbanas. Tandil: REUN, UNICEN.

Bond, G. y Gilliam, A. (1994). Introduction. En C. Bond \& A. Gilliam (eds.); Social Construction of the Past. Representation as Power. Nueva York: Routledge,

Conforti, M. (2013). La comunicación pública de la ciencia y su importancia en la valoración del patrimonio arqueológico. En M. Endere \& C. Mariano (eds.); Temas de Patrimonio Cultural. Tandil: UNICEN.

Erlandson, D. (1993). Doing natulalistic inquary. Londres: Sage.

Endere, M. (2009). Algunas reflexiones acerca del patrimonio. En M. Endere \& J. Prado (eds.); Patrimonio, ciencia y comunidad. Su abordaje en los partidos de Azul, Olavarría y Tandil. Tandil: UNICEN. 


\section{María Eugenia Conforti, Griselda Lemiez, María Vanesa Giacomasso, María Luz Endere}

Galeano Marín, M. (2004). Estrategias de investigación social cualitativa. El giro en la mirada. Medellín: La Carreta Editores.

García Canclini, N. (1999). Los usos sociales del patrimonio cultural. En E. Aguilar Criado (ed.); Patrimonio etnológico. Nuevas perspectivas de estudio. Sevilla: Consejería de la Cultura, Junta de Andalucía.

Giacomasso, M., Lemiez, G. y Conforti, M. (2019). Comunicación, patrimonio e identidad. El discurso de la prensa en torno a la Fiesta Nacional del Cemento en la ciudad de Olavarría, Buenos Aires (Argentina). Iconos. Revista de Ciencias Sociales (en prensa).

Giménez, G. (2007). Estudios sobre la cultura y las identidades sociales. México D.F.: Conaculta/ITESO.

Gravano, A. (2005). Palimpsesto urbano. Sobre-escritura de huellas diacrónicas de la ciudad imaginada". En A. Gravano (comp.); Imaginarios sociales de la ciudad media. Tandil: UNICEN.

Gravano, A. (2015). Tres hipótesis sobre la relación entre sistema urbano e imaginarios de ciudades medias. En A. Gravano \& Silvia Boggi (eds.); Ciudades vividas. Sistemas e imaginarios de ciudades medias bonaerenses. Buenos Aires: Editorial café de las ciudades.

Grimson, A. (2000). Interculturalidad y Comunicación. Buenos Aires: Grupo Editorial Norma.

Hernández Ramírez, M. y Ruiz Ballesteros, E. (2005a). Apropiación patrimonial en contextos mineros de Andalucía. Revista de Antropología 2: 103-127.

Hernández Ramírez, M. y Ruiz Ballesteros, E. (2005b). Intervenciones sobre el patrimonio minero en Andalucía: análisis de los procesos de patrimonialización. Anuario de Etnología Andaluza LX (2): 110-123.

ICOMOS (1999). Carta Internacional sobre Turismo Cultural. La Gestión del Turismo en los sitios con Patrimonio Significativo. https://www.icomos.org/charters/tourism sp.pdf

ICOMOS - TICCIH (2011). Principios de Dublín para la Conservación de Sitios, Estructuras, Áreas y Paisajes del Patrimonio Industrial. http://www.ticcih.es/wpcontent/uploads/2012/03/GA2011 ICOMOS TICCIH joint principles EN FR fin al 20120110.pdf 


\section{Prácticas patrimoniales en el contexto de la celebración por el centenario del primer despacho de cemento en Argentina}

Lemiez, G. (2013). Relaciones laborales paternalistas en la industria del cemento. España: Fundación Universitaria Andaluza Inca Garcilaso.

Lemiez, G., Conforti, M. y Giacomasso, M. (2019). Historia local, patrimonio cultural y medios de comunicación. El rol de la prensa en la construcción de una identidad industrial en el centro de la provincia de Buenos Aires, Argentina. Revista Historia Regional 40:1-14.

Lowenthal, D. (1998). The Heritage Crusade and the Spoils of History. Cambridge: Cambridge University Press.

Municipalidad de Olavarría (2016). Libro de Olavarría. Subsecretaría de Comunicación y Dirección de Comunicación Institucional. Olavarría: Municipalidad de Olavarría.

Paz, C. (2009). El desarrollo de la minería en el partido de Olavarría. Su abordaje desde la arqueología industrial. En M. Endere \& J. Prado (eds.); Patrimonio, Ciencia y Comunidad. Su abordaje en los partidos de azul, Olavarría y Tandil. Tandil: UNICEN.

Pérez Serrano, G. (1994). Investigación cualitativa retos e interrogantes. Madrid: La Muralla.

Prats, LL. (2000). El concepto de Patrimonio Cultural. Cuadernos de Antropología Social 11: 115-135.

Prats, LL. (2007). Antropología y Patrimonio. Barcelona: Editorial Ariel.

Richards, G. (2000). Cultural Tourism. In P. McManus (ed.); Archaeological Display and the Public. Museology and Interpretation. London: Archetype Publications.

Rojek, C and Urry, J. (1997). Touring Cultures. Transformations of Travel and Theory. London: Routledge.

Rosas Mantecón, A. (2005). Las disputas por el patrimonio. Transformaciones analíticas y contextuales de la problemática patrimonial en México. En N. García Canclini (ed.); La antropología urbana en México, México: Fondo de Cultura Económica.

UNESCO (2014). Gestión del Patrimonio Mundial Cultural. París: UNESCO,

Uribe, M. (1993). Los materiales de la memoria. Investigación cualitativa: confrontación y perspectiva. Medellín: Universidad de Antioquia.

Samuel, R. (1994). Theatres of Memory: Past and Present in Contemporary Culture. Londres: Verso. 
María Eugenia Conforti, Griselda Lemiez, María Vanesa Giacomasso, María Luz Endere

Sierra Álvarez, J. (1990). El obrero soñado. Ensayo sobre el paternalismo industrial (Asturias, 1860-1917). Madrid: Siglo veintiuno editores.

Smith, L. (2006). Uses of Heritage. Londres: Routledge.

Stake, R. (1994). Case studies. En N. Denzin \& Y. Lincoln (eds.); Handbook of qualitative research. Londres: Sage.

Vélez Restrepo, 0. y Galeano Marín, M. (2002). Estado del arte sobre fuentes documentales en investigación cualitativa. Medellín: Universidad de Antioquia.

Wicke, C., Berger, S. y Golombek, J. (2018). Industrial Heritage and Regional Identities. Routledge: Londres.

Woods, P. (1987). La escuela por dentro. La etnografía en la investigación educativa. Barcelona: Paidós.

Recibido: 06/01/2020

Evaluado: $20 / 02 / 2020$

Versión Final: 03/04/2020 